\title{
Spontaneous Bacterial Peritonitis Secondary to Cirrhosis of the Liver due to Echinococcosis: Case Report in Brazilian Indigenous
}

\begin{abstract}
Klinger Soares Faíco-Filho*, Diogo Boldim Ferreira and Eduardo Alexandrino Medeiros
Department of Internal Medicine, Division of Infectious Diseases, Universidade Federal de São Paulo (UNIFESP),
\end{abstract} Escola Paulista de Medicina (EPM), Brazil

\begin{abstract}
Background: Echinococcosis is an endemic disease in the Neotropical region of the Americas caused by Echinococcus spp. Most of the cases come from the Amazon region, where a disease is popularly called "paca disease", due to the population's habit of eating the meat of Cuniculus paca.

Case Report: We report 72-year-old Indigenous male presents cirrhosis complications caused by echinococcosis since 2010 confirmed by serological examination (titer 1:2560) and inactive cysts in imaging methods.

Conclusion: Inactive cysts in echinococcosis are a source of complications such as liver cirrhosis and spontaneous bacterial peritonitis.
\end{abstract}

Keywords: Echinococcus spp; Echinococcosis; Cirrhosis

\section{Background}

OPEN ACCESS

*Correspondence:

Klinger Soares Faíco-Filho, Department of Internal Medicine, Division of Infectious Diseases, Universidade Federal de São Paulo (UNIFESP), Escola Paulista de Medicina (EPM), São Paulo, SP, Brazil,

E-mail:klingerfaiko@hotmail.com Received Date: 16 Aug 2021

Accepted Date: 21 Sep 2021

Published Date: 24 Sep 2021

Citation:

Faíco-Filho KS, Ferreira DB, Medeiros EA. Spontaneous Bacterial Peritonitis Secondary to Cirrhosis of the Liver due to Echinococcosis: Case Report in Brazilian Indigenous. Ann Clin Case

Rep. 2021; 6: 1999.

ISSN: 2474-1655

Copyright $₫ 2021$ Klinger Soares Faíco-Filho. This is an open access article distributed under the Creative Commons Attribution License, which permits unrestricted use, distribution,

and reproduction in any medium, provided the original work is properly

cited.
Echinococcosis is a zoonosis caused by the larval form of Echinococcus spp. One of these species is Equinococcus vogeli, which is responsible for the polycystic form of the disease. Humans are not part of the life cycle of this parasite but can be infected if they ingest the larvae, thus becoming accidental intermediate hosts. The organs most affected by the parasite are the liver and lungs. Hydatid cysts may rupture, can become secondarily infected, or may infect other organs [1-3].

\section{Case Presentation}

A 72-year-old Indigenous Brazilian male, group Metunktire in Xingu, with echinococcosis since 2010 due to eating paca meat (Cuniculus paca). His diagnosis was confirmed by serological examination (titer 1:2560) and he received treatment with albendazole at the time. He was admitted to the emergency room with symptoms of increasing progressive abdominal volume accompanied by dyspnea with small efforts, edema of the lower limbs and diffuses abdominal pain, which persisted for 5 months before being admitted. The patient presented with BP 90/60 mmHg, respiratory rate $28 \mathrm{irpm}$, dehydration $2+/ 4+$, presence of jugular stasis $2+/ 4+$, and hepatojugular reflux. Pulmonary auscultation revealed bibasal crepitations in the lower third. Globose abdomen with painful palpation was observed. Abdominal tomography and ultrasound were performed, showing signs of chronic hepatopathy, presence of multiple diffuse hypodense nodules in the hepatic parenchyma, many with peripheral parietal calcification compatible with grade CE4 inactive echinococcosis. The largest of these nodules measured approximately $2.6 \mathrm{~cm}$ and was located in segment III. Other hypodense nodules with similar characteristics to the hepatic nodules were observed in the subhepatic region (measuring up to $3.2 \mathrm{~cm}$ ) and in the mesentery root (measuring up to $4 \mathrm{~cm}$ ). There was presence of accentuated ascites with centralization of small bowel loops. Chest tomography showed bilateral lobulated pulmonary nodules (measuring up to $3 \mathrm{~cm}$ ) with predominance in the left hemithorax and with fluid attenuation probably related to echinococcosis (Figure 1). Diagnostic paracentesis was then conducted, followed by aspiration of 6 I. Analysis of the ascitic fluid showed 4,080 cells (neutrophils 71\%; lymphocytes 6\%; mesotheliocytes $23 \%$ ) glucose 97 $\mathrm{mg} / \mathrm{dL}$; total protein $2.05 \mathrm{~g} / \mathrm{dL}$ and albumin $0.7 \mathrm{~g} / \mathrm{dL}$. Other causes for cirrhosis have been excluded

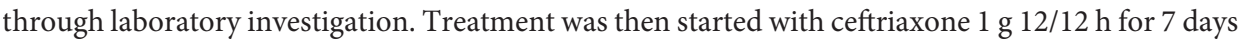
and intravenous albumin. 


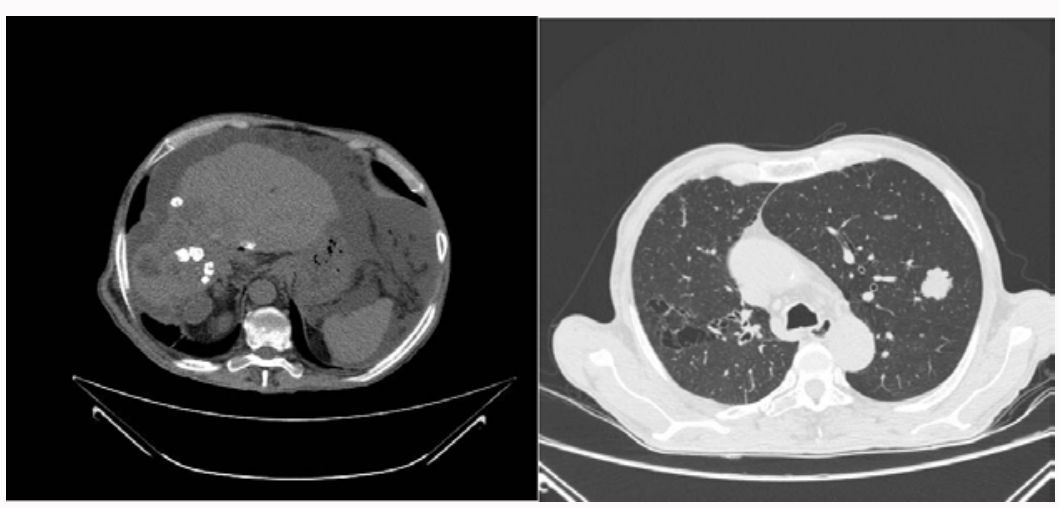

Figure 1: Abdominal tomography and chest tomography with nodules.

\section{Discussion and Conclusions}

The case presented demonstrates one of the complications of echinococcosis, which is liver cirrhosis. As reported, the patient had a 10-year course of disease, with cysts in inactive form. The World Health Organization classifies cysts based on their characteristics, with grades CE4 and CE5 being compatible with the inactive state $[4,5]$. Based on the identification of this complication, the patient started follow-up with complete propedeutics for liver cirrhosis, including upper digestive endoscopy and diureticotherapy after receiving treatment for the infection. Echinococcosis is an endemic disease in the Neotropical region of the Americas, which includes a northern region of Brazil, where a village of the reported patient is located. Most of the cases come from the Amazon region, where a disease is popularly called "paca disease", due to the population's habit of eating the meat of Cuniculus paca [6,7]. Albendazole, at a dose of $10 \mathrm{mg} / \mathrm{kg} /$ day to $15 \mathrm{mg} / \mathrm{kg} /$ day, is used for the pharmacological treatment of this disease. In adults, we commonly use a dose of 800 $\mathrm{mg} /$ day. Other combined therapies include Puncture-AspirationInjection-Respiration (PAIR), a technique that consists of destroying the germinal membrane of the cyst, followed by puncture, aspiration of the contents, injection of a scoliosis medication, such as $95 \%$ ethanol and hypertonic saline, and respiration. The main function of this combined technique is to prevent the onset of secondary disease, which occurred in the case of this patient. Surgical treatment is also an option to be analyzed, although the risks of surgery include intraoperative spread, recurrence in the long-term and anaphylactic reactions. In conclusion, we have demonstrated that inactive cysts in echinococcosis are a source of complications such as liver cirrhosis and spontaneous bacterial peritonitis. Whenever possible, combined therapy (pharmacological + PAIR) should be used to prevent these secondary diseases.

\section{References}

1. Eckert J, Thompson RCA. Historical aspects of Echinococcosis. Adv Parasitol. 2017;95:1-64.

2. Thompson RCA. Biology and systematics of Echinococcus. Adv Parasitol. 2017;95:65-109.

3. Thompson RCA, Lymbery AJ, organizadores. Echinococcus and hydatid disease. Wallingford, Oxon, UK: CAB International; 1995;477.

4. CDC - Centers for Disease Control and Prevention. CDC - Echinococcosis - Biology. 2012.

5. Siqueira NG, Santos-Jesus R, Tanajura D, Tavares-Neto J. Doença hidática policística: Análise secundária de dados. Rev Col Bras Cir. 2003;30(3):20515.

6. Siqueira NG, Siqueira CM, Rodrigues-Silva R, Soares MC, Póvoa MM. Polycystic Echinococcosis in the state of Acre, Brazil: Contribution to patient diagnosis, treatment and prognosis. Mem Inst Oswaldo Cruz. 2013;108(5):533-40.

7. Hemphill A, spicher M, Stadelmann B, Mueller J, Naguleswaran A, Gottstein B, et al. Innovative chemotherapeutical treatment options for alveolar and cystic Echinococcosis. Parasitology. 2007;134:1657-70. 